\title{
Tribological behavior and microstructural evolution of lubricating film of silver matrix self-lubricating nanocomposite
}

\author{
Xiao KANG ${ }^{1}$, Shuang YU ${ }^{2}$, Hailin YANG ${ }^{1}$, Yang SUN ${ }^{1}$, Lei ZHANG ${ }^{1, *}$ \\ ${ }^{I}$ State Key Laboratory for Powder Metallurgy, Central South University, Changsha 410083, China \\ ${ }^{2}$ Shanghai Institute of Astronautical Systems Engineering, Shanghai 201108, China \\ Received: 29 November 2019 / Revised: 20 March 2020 / Accepted: 07 May 2020 \\ (C) The author(s) 2020 .
}

\begin{abstract}
The aim of this study is to fabricate the nanocomposite with low friction and high wear resistance using binary solid lubricant particles. The microstructure and tribological performance of the nanocomposite are evaluated, and the composition and film thickness of the lubricating film are observed and analyzed by scanning electron microscopy (SEM) and X-ray photoelectron spectroscopy (XPS). The nanocomposite exhibited improved tribological properties with a friction coefficient as low as 0.12 and a low wear rate of $2.17 \times 10^{-6} \mathrm{~mm}^{3} /(\mathrm{N} \cdot \mathrm{m})$ in high-purity nitrogen atmosphere. Decreasing sliding speed can increase lubricating film thickness, and the thickest lubricating film is approximately $125 \mathrm{~nm}$. As the film thickness of the lubricating film exceeded $90 \mathrm{~nm}$, the friction coefficient curves became smooth. In compared with $\mathrm{WS}_{2}, \mathrm{MoS}_{2}$ can be more effective in forming the transfer layer on the worn surfaces at the initial stage of the tribological process.
\end{abstract}

Keywords: lubricating film; metal matrix self-lubricating composite; tribological behavior; binary solid lubricants; X-ray photoelectron spectroscopy (XPS)

\section{Introduction}

Transition-metal dichalcogenides (TMDs) are typical two-dimensional materials, which exhibit the lamellar structure [1, 2]. TMDs have the stronger covalent in-plane bonding between metal and chalcogen elements, but the weaker van der Waals bonding between crystal lamellar sheets [3]. The lamellar structure is easy to slip between crystal lamellar sheets due to the anisotropy crystal of TMDs [3-5]. As the typical solid lubricants, the addition of TMDs enhances the tribological properties of metal matrix self-lubricating composites (MMSCs), including $\mathrm{TiSe}_{2}, \mathrm{NbSe}_{2}, \mathrm{MoS}_{2}$ and $\mathrm{WS}_{2}$ [6-9]. Recently, MMSCs with low friction are widely used as bushes for industrial applications and sliding electrical contact materials $[10,11]$.
Owing to the excellent lubricating properties of binary solid lubricants, they were used to synthesize the composites with low friction coefficient and high wear resistance. Binary solid lubricants could effectively reduce abrasive wear and adhesive wear. As binary solid lubricants can generate more durable lubricating films, they can reduce the wear rates and friction coefficient of the materials [12-16]. Some materials containing the binary solid lubricants, such as $\mathrm{MoS}_{2}-\mathrm{Sb}_{2} \mathrm{O}_{3}-\mathrm{Au}$ composite coatings, $\mathrm{CoCrFeNi}-\mathrm{Ag}-$ $\mathrm{CaF}_{2}$ self-lubricating composite, $\mathrm{Ag}-\mathrm{MoS}_{2}$-graphite composites and $\mathrm{Cu}-\mathrm{NbSe}_{2}-\mathrm{CNT}$ composite, exhibit an improvement in tribological properties in comparison to the materials containing the single lubricant [13-16].

Currently, the tribological behavior of composites containing transition metal dichalcogenides has

* Corresponding author: Lei ZHANG, E-mail: zhanglei@csu.edu.cn 
been extensively studied. When the concentration of solid lubricants in metal matrix self-lubricating composites is greater than $5 \mathrm{wt} \%$, the lubricating effect of the solid lubricants is more pronounced, as reported by $\mathrm{Wu}$ et al. [17]. Xiao et al. [7] synthesized $\mathrm{Cu}-\mathrm{MoS}_{2}$ composites by hot-press sintering, and their results indicated that the friction coefficient and wear rate of $\mathrm{Cu}-\mathrm{MoS}_{2}$ composites reduced by $81.6 \%$ and $96.0 \%$ when the $\mathrm{MoS}_{2}$ content was increased from $0 \mathrm{vol} \%$ to $40 \mathrm{vol} \%$, respectively. More recently, lubricating films on worn surfaces have garnered significant attention [18-20]. Hu et al. [20] established an interactive friction model and reported that lubricant oil thickness decreased with increasing sliding speed and contact pressure. Additionally, the gradual reduction in thickness resulted in a conversion from a full film lubrication to a boundary lubrication and hence a deterioration in lubricating properties [20].

$\mathrm{Wu}$ et al. [21] synthesized $\mathrm{Ni}-\mathrm{MoS}_{2}$ composites and discovered that the coverage area of the lubricating film increased with $\mathrm{MoS}_{2}$ content, and the friction coefficient and wear rates decreased with increasing $\mathrm{MoS}_{2}$ content. The average area of the lubricating film and the wear-resistance increased with the lubricant concentration [20, 22]. In terms of hot-press sintering, Xiao et al. [23] prepared $\mathrm{Cu}-\mathrm{MoS}_{2}$ composites and reported that the lubricating film of $\mathrm{Cu}-\mathrm{MoS}_{2}$ composites was formed by a large amount of nanoscale $\mathrm{MoS}_{2}$. The film thickness of the lubricating film ranged from 33 to $100 \mathrm{~nm}$ [23]. However, most investigations have focused on the effects of lubricant content, sliding speed, and contact pressure on the performance of the lubricating film [18-25]. Reports on the lubricating film of metal matrix self-lubricating composites are limited, particularly those pertaining to the evolution of the lubricating film.

In the present work, a novel metal matrix selflubricating nanocomposite was fabricated by hotpress sintering. The nanoscale Ag powder, nanoscale $\mathrm{WS}_{2}$ powder, and microscale $\mathrm{MoS}_{2}$ powder were used to fabricate the nanocomposite with low friction and high wear-resistance. The lubricating film formed during sliding was investi-gated to determine the microstructural evolution, composition, and film thickness of the lubricating film, as well as the tribological properties of the nanocomposite.

\section{Experimental details}

\subsection{Materials}

The nanoscale Ag powder with an average size of $75 \mathrm{~nm}$, nanoscale $\mathrm{WS}_{2}$ powder with an average size of $80 \mathrm{~nm}$, and microscale $\mathrm{MoS}_{2}$ powder with an average size of $2 \mu \mathrm{m}$ were selected as the raw materials of $\mathrm{Ag}-10 \mathrm{WS}_{2}-5 \mathrm{MoS}_{2}$ (weight fraction) nanocomposite. To synthesize the nanocomposite, Ag powder, $\mathrm{WS}_{2}$ powder and $\mathrm{MoS}_{2}$ powder were put into the ball mill and mixed for $24 \mathrm{~h}$ at $120 \mathrm{rpm}$. Subsequently, $\mathrm{Ag}-10 \mathrm{WS}_{2}-5 \mathrm{MoS}_{2}$ powder was poured into graphite dies for hot-press sintering. Hot-press sintering was conducted using a custom-made furnace at $750{ }^{\circ} \mathrm{C}$ and $25 \mathrm{MPa}$ under a $\mathrm{N}_{2}$ atmosphere. The sintering specimens measured $\Phi 60 \mathrm{~mm} \times 3 \mathrm{~mm}$. Finally, individual samples were fabricated as cubes measuring $3 \mathrm{~mm} \times 3 \mathrm{~mm} \times 3 \mathrm{~mm}$ for tribological testing.

\subsection{Friction and wear testing}

The friction and wear testing of the nanocomposite were conducted using a tribometer (CSM Instruments, Peseux, Switzerland) with a pin-on-disc configuration. The nanocomposite with a hardness of $73.4 \mathrm{HB}$ was used as the pin, and the coin-silver disc (Ag10wt\% $\mathrm{Cu}$ ) with a diameter of $50 \mathrm{~mm}$ and a hardness of 120.3 HB was regard as the counter disc. Prior to the tests, the contact surfaces were cleaned with acetone and ethanol after polishing. The coin-silver discs had an average surface roughness as low as approximately $55 \mathrm{~nm}$. The friction and wear tests were with a sliding distance of $1000 \mathrm{~m}$ and an applied load of $1 \mathrm{~N}$, and the tests were performed in a high-purity nitrogen atmosphere with a purity of $99.9 \%$. The tests were conducted at room temperature. To further reveal the relationship between the sliding speeds and the friction and wear properties of the nanocomposite, the friction and wear tests were conducted at three sliding speeds within the range from 0.01 to $1.0 \mathrm{~m} / \mathrm{s}$. The wear rates and friction coefficients of the nanocomposite and disc were tested thrice, and average values were presented in this paper. The weight loss of the nanocomposite pins and coin-silver discs before and after the friction 
and wear tests was calculated by a digital microbalance, and wear rates were computed by Eq. (1):

$$
W=\Delta m /(P \rho s)
$$

where $W, \Delta m, P, \rho$, and $s$ are the wear rate, wear mass loss, normal load, specimen density, and sliding distance, respectively [26].

\subsection{Characterization}

The green body sample and sintered sample were measured by X-ray diffraction (XRD, D/max 2550, Japan) using $\mathrm{Cu}-\mathrm{K} \alpha$ radiation scanning. A distribution and a $2 \theta$ scanning rate were $10^{\circ}$ to $80^{\circ}$ and of $5 \% \mathrm{~min}$, respectively. The relative densities of the specimens were obtained using the Archimedes method. The raw powder, micro-structure, fracture surface and transfer film were investigated using a field-emission scanning electron microscope (SEM, Nova NanoSEM 230, USA) equipped with an energy dispersive spectroscopy (EDS, EDAX, USA) detector. Transmission electron microscope (TEM, Tecnai G2, USA) was used to analysis the interface of solid lubricants and silver matrix. The worn surface of the nanocomposite was measured by an X-ray photoelectron spectroscopy (XPS, K-Alpha, UK). $\mathrm{Ar}^{+}$ion etching was used to measure the film thickness of the lubricating films on the worn surfaces.

\section{Results and discussion}

\subsection{Microstructure}

Figure 1 shows SEM images of the raw powders used in the experiments. The average size of the nanoscale Ag powder was $75 \mathrm{~nm}$. The nanoscale $\mathrm{WS}_{2}$ powder was $80 \mathrm{~nm}$ in size. Furthermore, microscale $\mathrm{MoS}_{2}$ powder exhibited a layered structure with a mean size of $2 \mu \mathrm{m}$. As indicated in Fig. 2, the phases of the green body sample and sintered sample were measured by XRD. The sharp peaks located at $38.1^{\circ}$, $44.3^{\circ}, 64.4^{\circ}$, and $77.5^{\circ}$ corresponding to the $\mathrm{Ag}$ (111), (200), (220), and (311) planes of $\mathrm{Ag}$, and the typical peaks located at $14.3^{\circ}, 33.6^{\circ}, 39.5^{\circ}, 49.7^{\circ}$, and $58.4^{\circ}$ associating with the (002), (101), (103), (105), and (110) planes of WS2. It is confirmed that the reactions between the solid lubricants and silver matrix were inhibited during hot-press sintering,
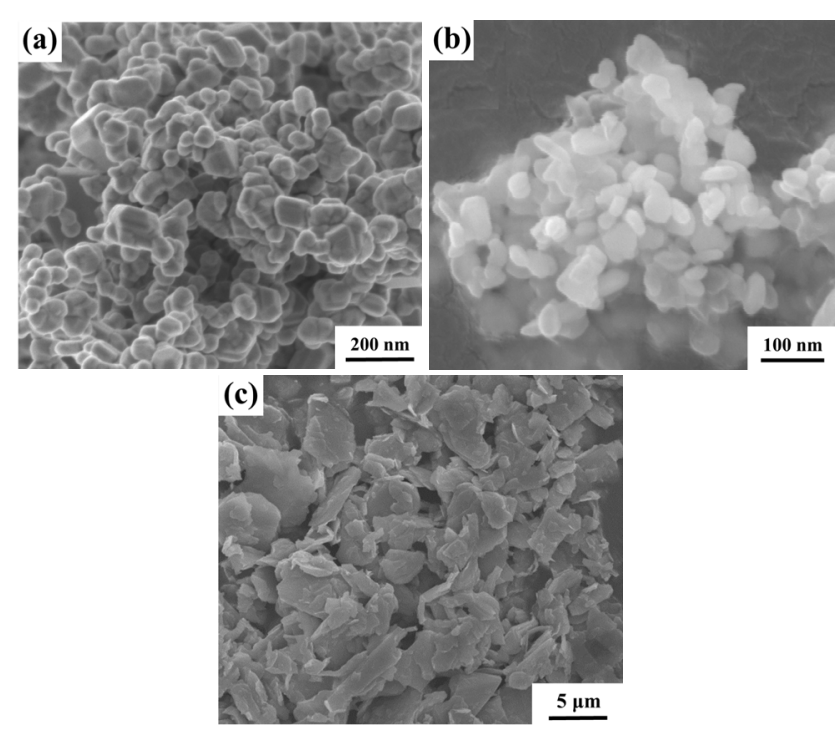

Fig. 1 SEM images of (a) Ag powder, (b) $\mathrm{WS}_{2}$ powder, and (c) $\mathrm{MoS}_{2}$ powder.

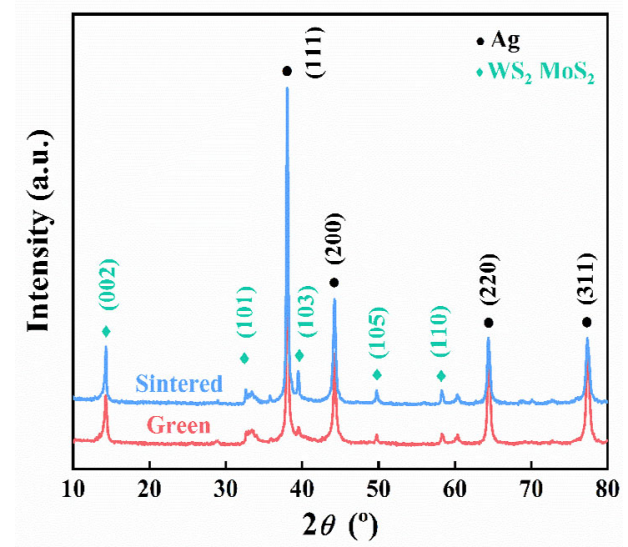

Fig. 2 XRD patterns of the green body sample and sintered sample after hot-pressing.

and other phases were not generated.

The typical microstructure of the nanocomposite is presented in Fig. 3. As shown in Fig. 3(a), the gray areas, white areas, and black areas are those of $\mathrm{Ag}$, $\mathrm{WS}_{2}$ and $\mathrm{MoS}_{2}$, respectively. The elemental mappings of Ag (Fig. 3(b)), S (Fig. 3(c)), W (Fig. 3(d)), and Mo (Fig. 3(e)) are presented. As shown, the $\mathrm{WS}_{2}$ and $\mathrm{MoS}_{2}$ powders are homogeneously distributed in the silver matrix. Nanoscale powders are easy to aggregate during ball milling process [27, 28], therefore, the nanoscale $\mathrm{WS}_{2}$ powder has various sizes in the nanocomposite. As presented in Fig. 3, no obvious hole was found at the interface of solid lubricants and Ag matrix, and the nanocomposite exhibited a high relative density of $99.0 \%$. Consequently, the interface of the solid lubricants 

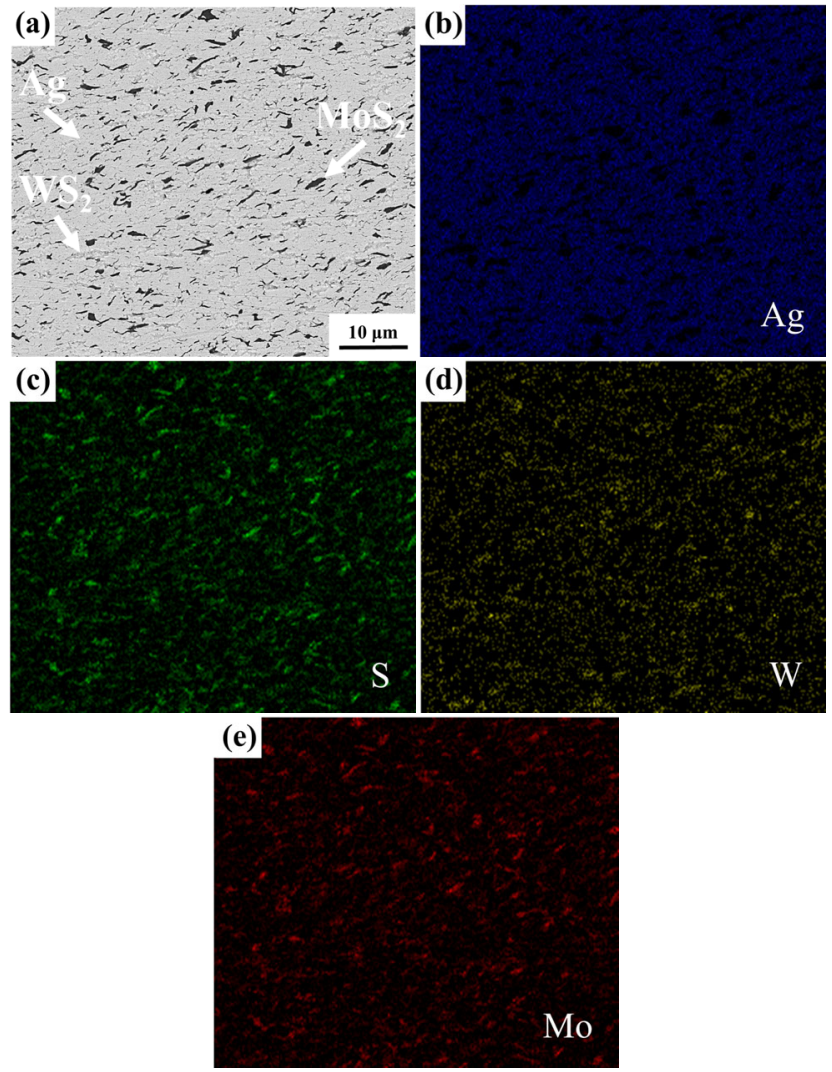

Fig. 3 Back scattering electron (BSE) images showing (a) microstructure and (b-e) EDS mappings of the $\mathrm{Ag}-\mathrm{WS}_{2}-\mathrm{MoS}_{2}$ nanocomposite
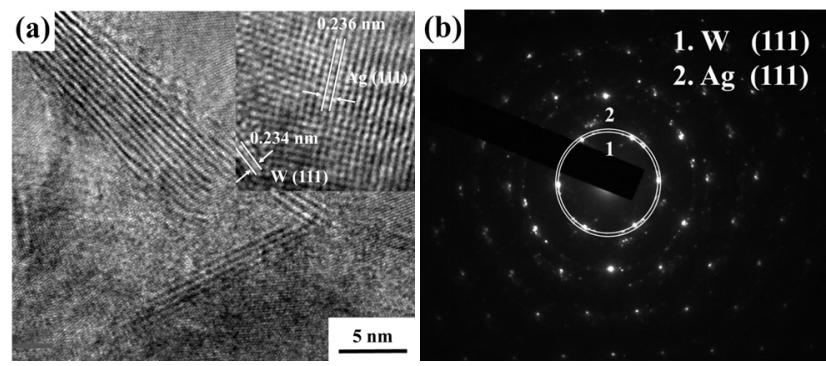

Fig. 4 TEM analysis of $\mathrm{Ag}-\mathrm{WS}_{2}-\mathrm{MoS}_{2}$ nanocomposite, including (a) high resolution transmission electron microscope (HRTEM) and (b) SAED patterns of $\mathrm{W}$ and Ag.

and Ag matrix had a good interfacial bonding by using the hot-press sintering [8]. Transmission electron microscope (TEM) is performed to identify the composition selected area electron diffraction
(SAED) presents clear spots without splitting, indicating the similar lattice of W and Ag. W (111) and Ag (111) had the interplanar distances of 0.234 and $0.236 \mathrm{~nm}$, respectively, and the mismatch of the interplanar distances was $0.85 \%$. Consequently, the coherent structure was result from the small lattice mismatch at the interface of $W$ (111) and Ag (111), exhibiting the certain orientation relationship. The interface between $\mathrm{W}$ and $\mathrm{Ag}$ is semi-coherent, and the semicoherent interface results in an improvement of the interfacial bonding between the solid lubricants and Ag matrix and an increase in the mechanical property.

\subsection{Mechanical properties}

Table 1 lists the hardness, bending strength, and relative density of the $\mathrm{Ag}-10 \mathrm{WS}_{2}-5 \mathrm{MoS}_{2}$ nanocomposite, comparing with the mechanical properties of other silver matrix self-lubricating composites containing different compositions [10,17]. As shown in Table 1 , the nanocomposite had a hardness of $73.4 \mathrm{HB}$ and a bending strength of $187.5 \mathrm{MPa}$. In comparison to other silver matrix self-lubricating composites, the nanocomposite had an improvement in the bending strength and hardness [10,17]. Moreover, the enhanced hot-press sintering resulted in a high density (99.0\%) of the nanocomposite. An improvement in bending strength of the nanocomposite was attributed to no obvious hole between the interface of solid lubricants and Ag matrix. The semi-coherent interface resulted in an improvement of the interfacial bonding between the solid lubricants and Ag matrix, thereby the nanocomposite achieved an improvement in the mechanical properties [29]. To further understand the mechanical properties of the nanocomposite, Fig. 5 shows the fracture morphologies of the nanocomposite after the bending strength test. The enhanced mechanical properties of the nanocomposite were attributed to the large quantities of dimples. Moreover, micro-cracks were generated at the

Table 1 Hardness, bending strength and relative density of the typical silver matrix self-lubricating composites.

\begin{tabular}{lcccc}
\hline Composition & Bending strength (MPa) & Hardness (HB) & Relative density (\%) & References \\
\hline $\mathrm{Ag}-10 \mathrm{WS}_{2}-5 \mathrm{MoS}_{2}$ & 187.5 & 73.4 & 99.0 & Present work \\
$\mathrm{AgCu}-8 \mathrm{MoS}_{2}$ & 165.3 & 37.2 & 97.1 & {$[10]$} \\
$\mathrm{AgCu}-16 \mathrm{WS}_{2}$ & 160.0 & 57.8 & 98.6 & {$[17]$} \\
\hline
\end{tabular}




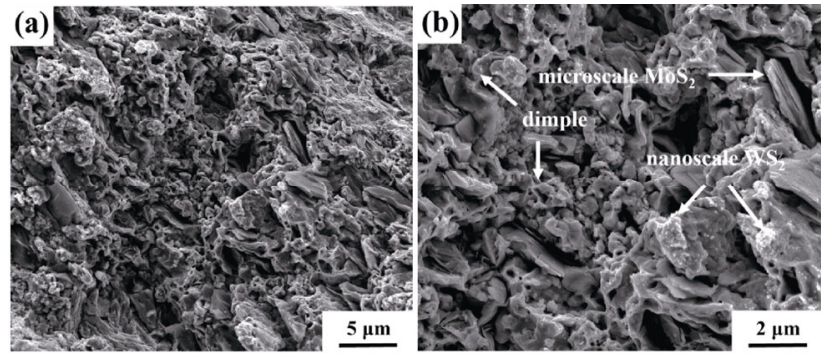

Fig. 5 Fracture morphology of the nanocomposite after the bending strength test.

interface of $\mathrm{Ag}$ matrix, $\mathrm{WS}_{2}$ powder and $\mathrm{MoS}_{2}$ powder. As indicated in Fig. 3, the analogous uniform structure can inhibit micro-cracks, thereby the nano composite has an improvement in the mechanical properties [30].

\subsection{Wear and friction properties}

The friction coefficient curves with different speeds are shown in Fig. 6(a). In the initial stage, the friction coefficient curves decreased significantly and then kept constant with an increase in the sliding distance. The average values of the friction coefficients and wear rates are presented in Fig. 6(b). The sliding speed had a slight effect on the average friction coefficient of the nanocomposite, and the average friction coefficients ranged from $0.12-0.16$. When the sliding speed reached $0.1 \mathrm{~m} / \mathrm{s}$, the lowest friction coefficient was 0.12 . The sliding speed had an important influence on the wear rates of the nanocomposite, and the wear rates decreased with an increase in the sliding speed. The lowest wear rate of the nanocomposite was $2.17 \times 10^{-6} \mathrm{~mm}^{3} /(\mathrm{N} \cdot \mathrm{m})$ in a high-purity nitrogen atmosphere.

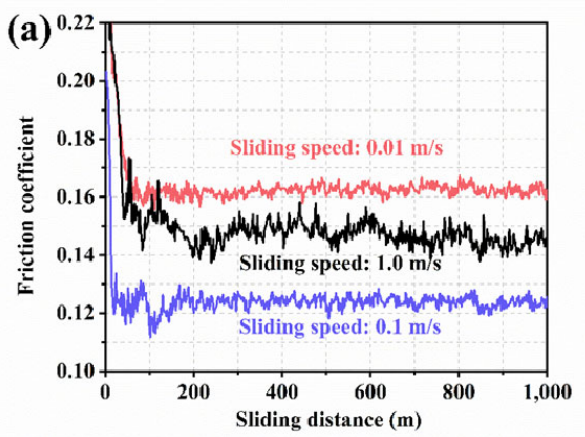

Recently, the investigation of lubricating films and their influence on the tribological behaviors of the composites have been reported in several studies $[8,9,23]$. Their researches indicated that the lubricating films were formed on worn surfaces of the composites during the friction and wear process, reducing the wear rates and friction coefficients. The addition of solid lubricant, such as $\mathrm{MoS}_{2}$ and $\mathrm{NbSe}_{2}$, promotes the formation of lubricating films, enhancing the wear resistance of the materials [6-9]. Moreover, the direct contact between the pin and disc is prevented by the lubricating film, and the adhesive wear of the materials was inhibited [20, 31]. Lots of solid lubricants in the lubricating film ensure the ultralow shear force of the lubricating film, decreasing the friction coefficient of the materials.

To identify the film thickness and composition of the lubricating films, XPS analyses were used to analyze the lubricating films on worn surfaces of the nanocomposite, and $\mathrm{Ar}^{+}$beam affiliated by XPS was used to etch the lubricating film in the depth direction to identify the film thickness of the lubricating film. Evolutions of XPS spectra in the depth direction are presented Fig. 7. As indicated in Fig. 7(a), the two peaks located at 367.3 and $373.4 \mathrm{eV}$ are assigned to $\mathrm{Ag} 3 \mathrm{~d}$. The peak intensity of $\mathrm{Ag} \mathrm{3d}$ increased with an increase in $\mathrm{Ar}^{+}$ion etching time. The $\mathrm{W} 4 \mathrm{f}$ spectrum is dominated by the typical peak centered at $30.8 \mathrm{eV}$, as indicated in Fig. 7(b). Figures 7(c) and 7(d) show that the peak at $227.3 \mathrm{eV}$ is assigned to Mo $3 \mathrm{~d}$, and the peak at the binding energy of $162.2 \mathrm{eV}$ is assigned to $\mathrm{S} 2 \mathrm{p}$. The W 4f, Mo 3d, and S 2p peak intensities decreased

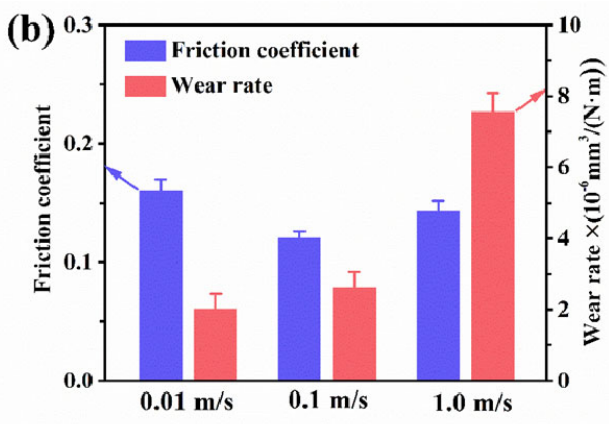

Fig. 6 (a) Friction coefficient curves and (b) average friction coefficient and wear rates of the nanocomposite in high-purity nitrogen atmosphere. 

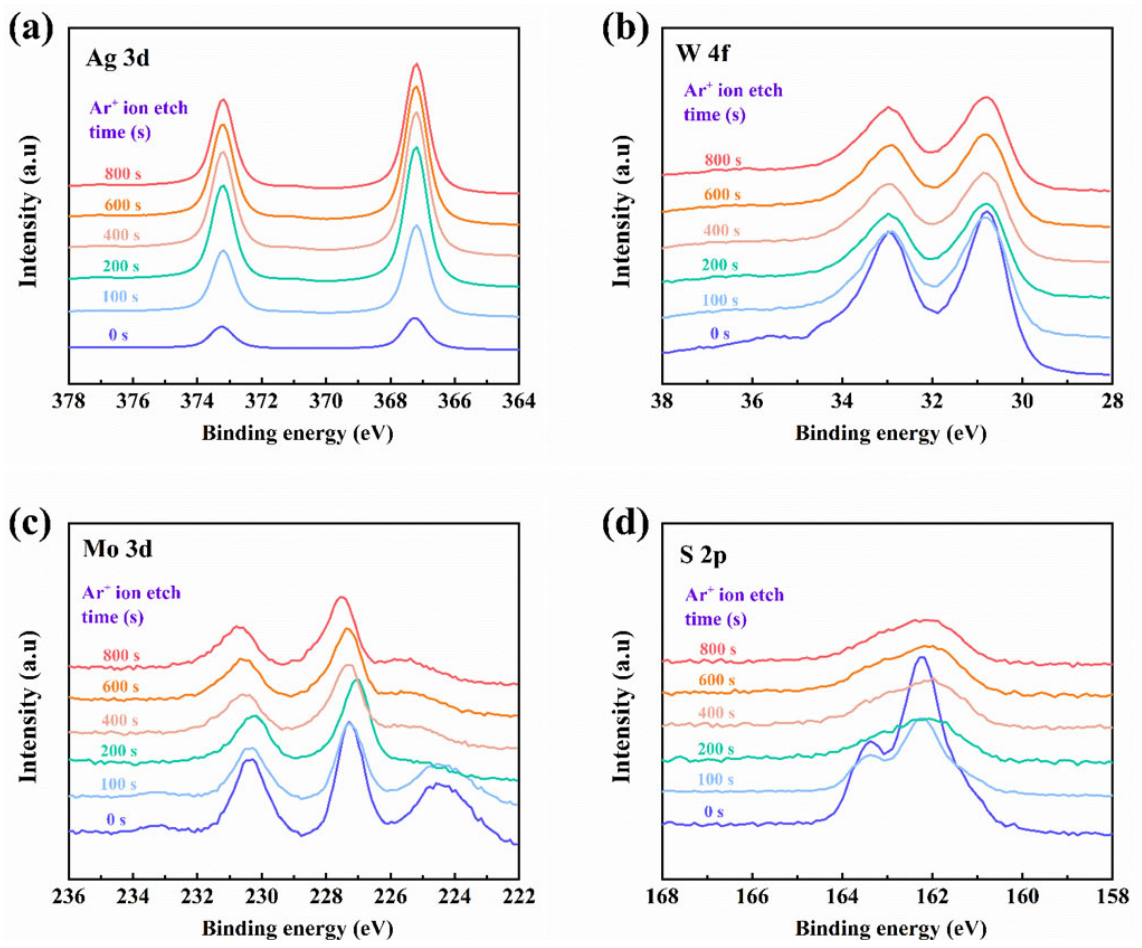

Fig. 7 Evolution of XPS spectra of the worn surface of the nanocomposite in the depth direction.

with an increase in $\mathrm{Ar}^{+}$ion etching time. It is indicated that the solid lubricant content shows a decrease in the depth direction. The peak intensity of $\mathrm{Ag} 3 \mathrm{~d}$ had an inverse tendency in comparison to the peak intensity of W 4f, Mo 3d, and S 2p. The peak intensities evolution of the Ag 3d (Fig. 7(a)), W 4f + Mo 3d (Figs. 7(b) and 7(c)), and S 2p (Fig. 7(d)) are summarized, as indicated in Fig. 8(a). As the accumulated $\mathrm{Ar}^{+}$ion etching time exceeds $400 \mathrm{~s}$, the peak intensities of the W $4 \mathrm{f}, \mathrm{Mo} 3 \mathrm{~d}$, and $\mathrm{S} 2 \mathrm{p}$ speed of the Ag matrix composites is approximately $0.35 \mathrm{~nm} / \mathrm{s}[32,33]$, the semiquantitative calculation of the film thickness of the lubricating film is less than $140 \mathrm{~nm}(0.01 \mathrm{~m} / \mathrm{s})$. Likewise, the lubricating film exhibits a film thickness of less than $140 \mathrm{~nm}$ $(0.1 \mathrm{~m} / \mathrm{s})$, as indicated in Fig. 8(b). In Fig. 8(c), as accumulated $\mathrm{Ar}^{+}$ion etching time exceeds $200 \mathrm{~s}$, the film thickness of the lubricating film is less than $70 \mathrm{~nm}(1.0 \mathrm{~m} / \mathrm{s})$. The microscale $\mathrm{MoS}_{2}$ and nanoscale $\mathrm{WS}_{2}$ are transferred to the worn surfaces during the friction and wear process, and then the lubricating film is formed on the worn surfaces. The lubricating film enhances the peak intensities of $S 2 p$, Mo 3d, and W 4f, whereas it decreases the peak intensity of $\mathrm{Ag} 3 \mathrm{~d}$ on the outmost surface. The peak intensities of S $2 \mathrm{p}$, Mo $3 \mathrm{~d}$, and $\mathrm{W} 4 \mathrm{f}$ decrease with an increase in the accumulated $\mathrm{Ar}^{+}$ ion etching time, whereas that of $\mathrm{Ag} 3 \mathrm{~d}$ shows an (a)

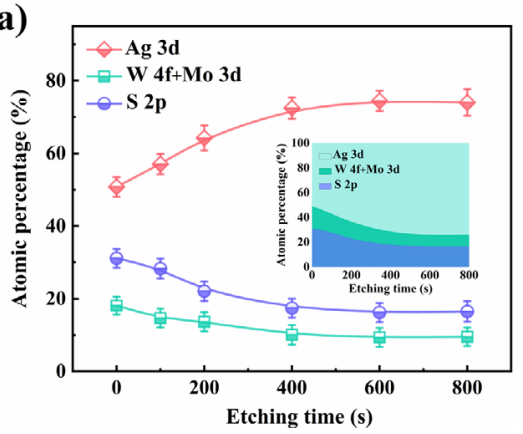

(b)

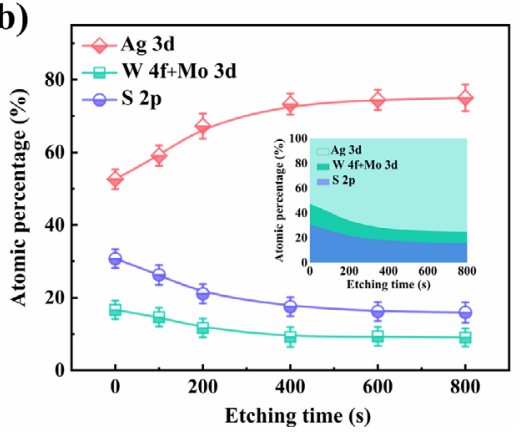

(c)

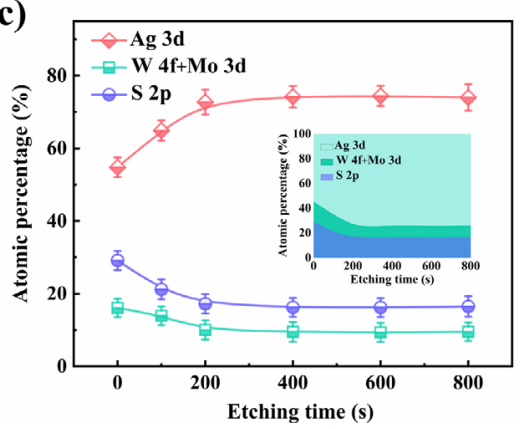

Fig. 8 Evolution of elemental atomic percentages of the worn surface in the depth direction. The sliding speeds are (a) (b) (c) $0.01,0.1$ and $1.0 \mathrm{~m} / \mathrm{s}$. 
increase with further etching.

The evolution of the film thickness of the lubricating film affects the evolution of the friction coefficient, which is affected by the sliding distance, sliding speed, and lubricant content [20]. According to the values and variations of friction coefficients, the evolution of the friction coefficient curves can be classified into three stages: the initial, transitional, and steady stages. Generally, in the initial stage, the friction coefficient shows a rapid decrease with increasing lubricating film thickness. In the steady stage, the friction coefficient remains constant. Figure 9 presents the friction coefficient curves and the lubricating film thickness as a function of the sliding distance with different sliding speeds. As shown, in the initial stage, the friction coefficient decreased and the lubricating film thickness increased significantly. The friction coefficient curves showed a fluctuation in the transitional stage, and the lubricating film remained relatively constant with an increase in the sliding distance.

In the steady stage, the friction coefficient curves decreased and then increased with increasing sliding distance, as presented in Fig. 9. This was resulted from the variation in the lubricating film thickness, and the friction coefficient decreased and then increase with increasing lubricating film thickness [33]. In the steady stage, the friction coefficient curves in Figs. 9(a) and 9(b) are smooth compared with those in Fig. 9(c). This can be attributed to the generation of thicker lubricating films at lower sliding speeds. When the lubricating film thickness exceeded $90 \mathrm{~nm}$, a smooth friction coefficient was achieved. An increase in the thickness resulted in a transition from boundary lubrication to full film formation and smoother friction coefficient curves; hence, balance was attained between the formation and consumption of the lubricating film [33, 34].

For comparison, Fig. 9(d) shows the variation in the lubricating film thickness with decreasing sliding speed. The thickest lubricating film (approximately $125 \mathrm{~nm})$ was obtained at the lowest speed (0.01 $\mathrm{m} / \mathrm{s})$. It has been reported that a decreasing sliding speed decreases the temperature of worn surfaces and consequently reduces the consumption of the lubricating film $[12,20]$. A low friction coefficient and smooth friction coefficient curves are desirable during the tribological processes of metal matrix
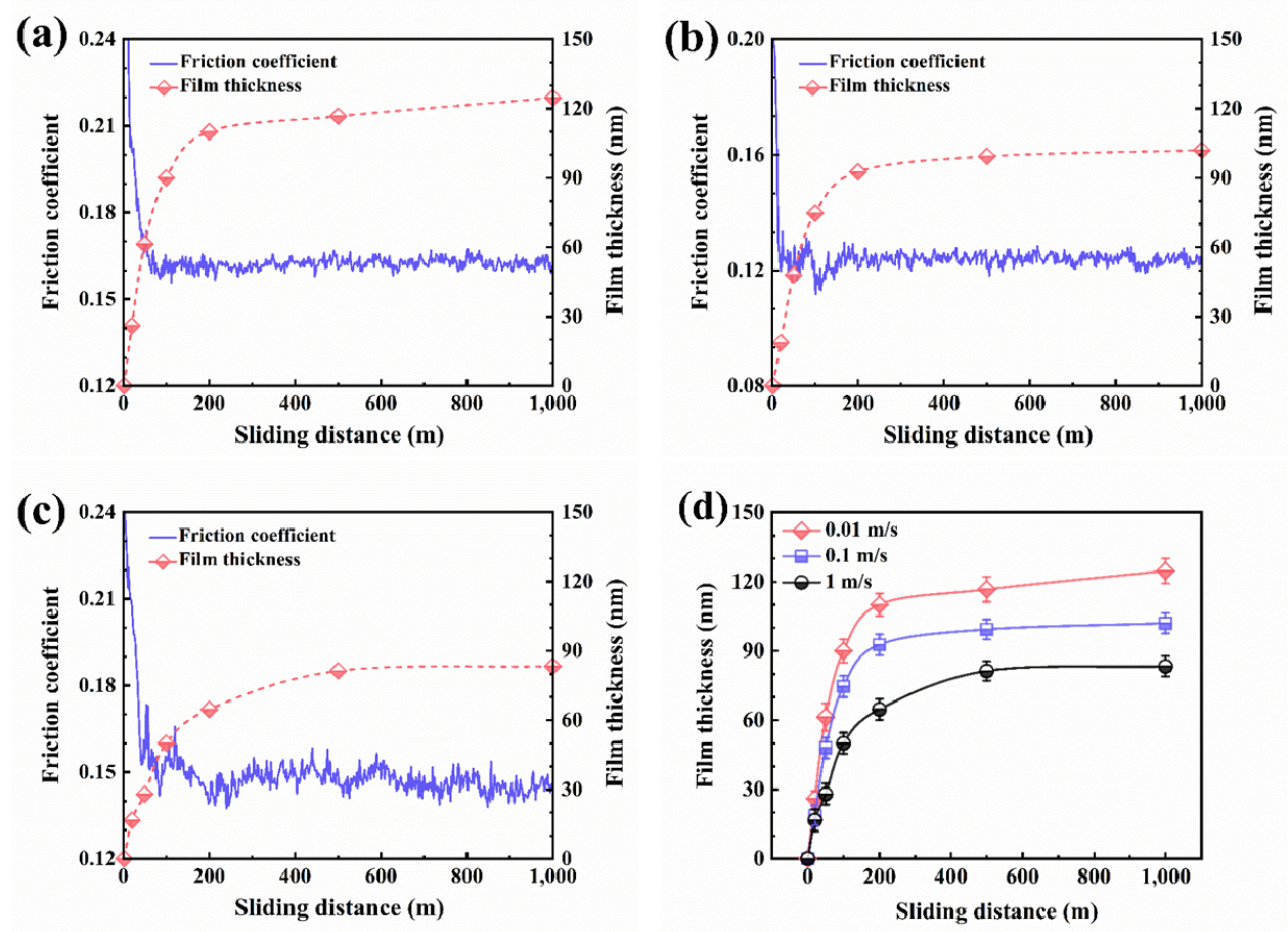

Fig. 9 Evolution of friction coefficient curves and lubricating film thickness as function of the sliding distance with the sliding speed of (a) $0.01 \mathrm{~m} / \mathrm{s}$, (b) $0.1 \mathrm{~m} / \mathrm{s}$, and (c) $1 \mathrm{~m} / \mathrm{s}$, and (d) effect of sliding speed on evolution of film thickness. 
self-lubricating composites. A stable lubricating film often results in a stable friction coefficient [20]. During sliding, solid lubricants in the nanocomposite adhered to the worn surface of the counter disc, thereby generating a lubricating film [35]. The lubricating film containing rich solid lubricants can shear easily, which reduces the friction coefficient of the nanocomposite $[3,23]$. The transfer film on the worn counter disc surface has also been reported in other studies on metal matrix self-lubricating composites [7, 13, 23].

To understand the evolution of the transfer film more effectively, Fig. 10 presents the EDS mappings of the worn surfaces of the counter disc with sliding distances of 50-1000 m. S, Mo, and W elements were detected in the transfer film, and the solid lubricant content of the transfer films increased with an increase in the sliding distance, as presented in Fig. 10. The worn surface was covered by a thinner transfer film in the initial stage $(0-100 \mathrm{~m})$, indicating that the transfer film provides limited lubricating properties in this stage [20], however, a thicker transfer film was formed on the worn surface in the transitional stage (100-200 m). In the steady stage (over $500 \mathrm{~m}$ ), the transfer film covered a large proportion of the worn surfaces. There are many solid lubricants in the transfer film, therefore, the transfer film provides the sufficient lubricating property. The friction coefficient curve was smooth in the steady stage, as shown in Fig. 9(b).

The variation in the atomic percentage of the transfer film is shown in Fig. 11. The atomic percentage of W slowly increased in the initial stage and a rapid increase in the transitional stage. However, the Mo element showed a significant increase at the initial stage, and the Mo element showed a slight increase with an increase in the sliding distance. The atomic percentage of Mo was higher than that of $\mathrm{W}$ at the initial and transitional stages; however, the atomic percentages of Mo and W were similar in the steady
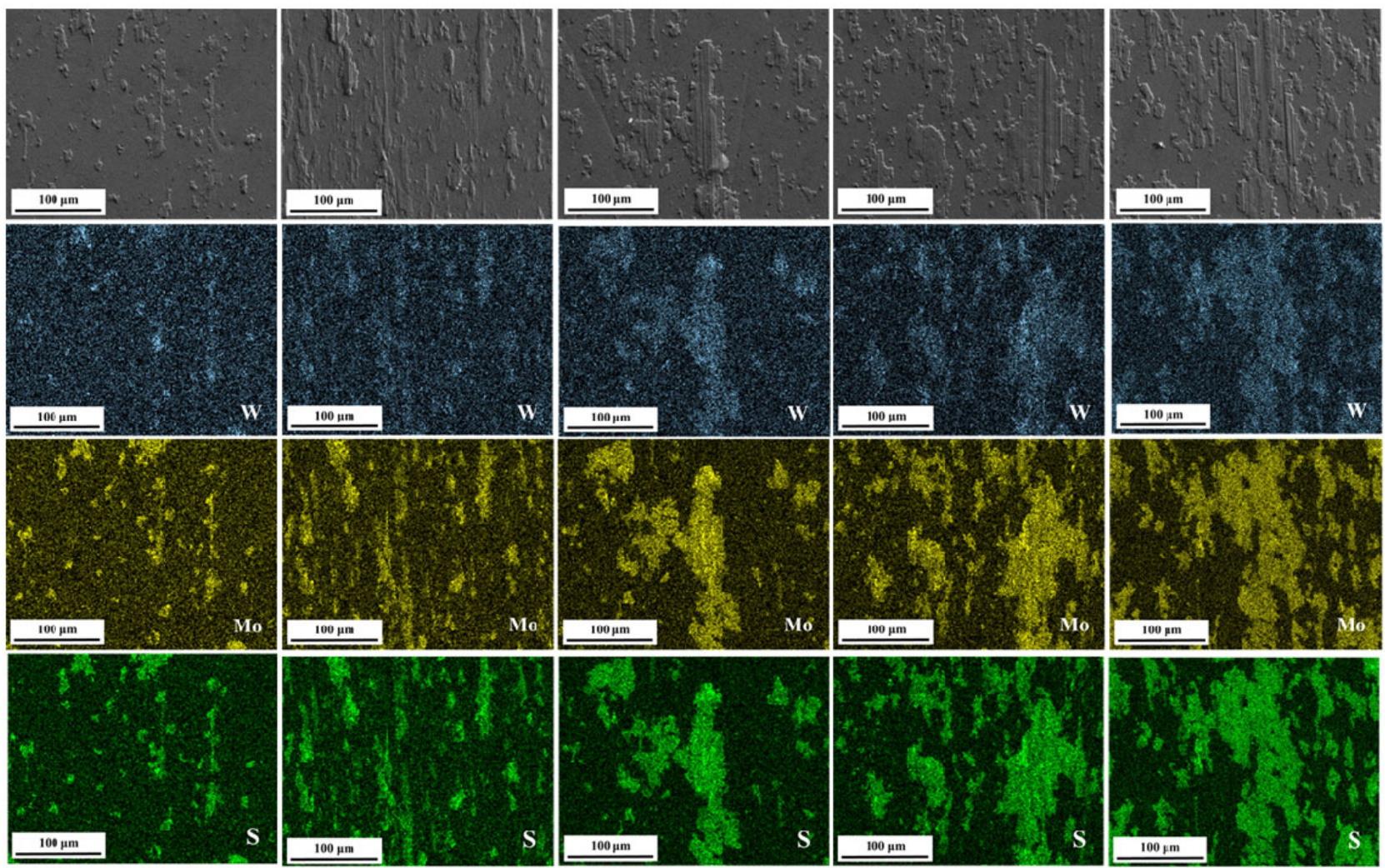

$50 \mathrm{~m}$ $100 \mathrm{~m}$

$200 \mathrm{~m}$

$500 \mathrm{~m}$
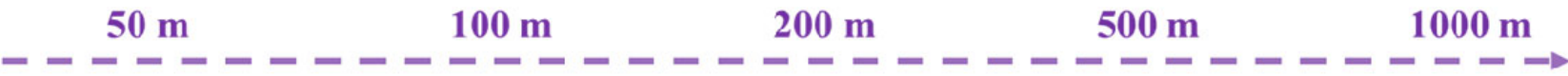

Fig. 10 SEM-EDS mappings show the transfer film evolution within the sliding distances ranged from 50 to $1,000 \mathrm{~m}$, and the sliding speed is $0.1 \mathrm{~m} / \mathrm{s}$. 


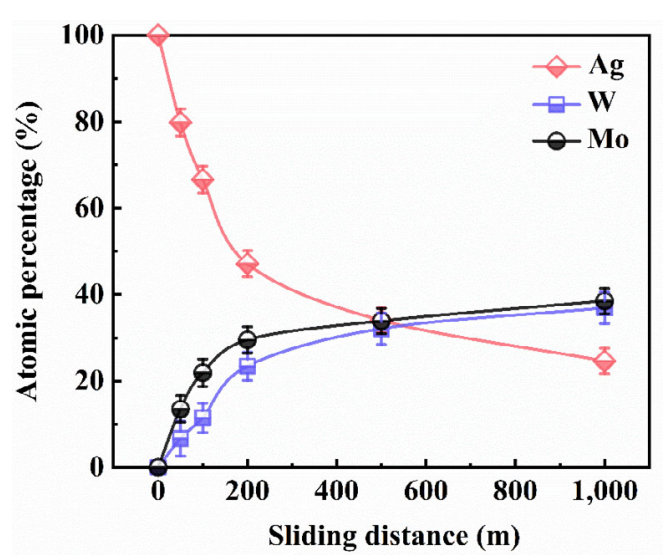

Fig. 11 Evolution of elemental atomic percentages of the transfer films within the sliding distances ranged from 50 to $1,000 \mathrm{~m}$.

stage. Owing to the excellent plastic deformation ability of silver, binary solid lubricants are easier to transfer to the outmost surface. The microscale $\mathrm{MoS}_{2}$ and nanoscale $\mathrm{WS}_{2}$ were transferred to the outmost surface under shear force and contact pressure, forming the transfer film [36]. Meanwhile, the transfer film contained solid lubricant reduced the wear rates of the materials, as well as inhibited the abrasive and adhesive wear [35]. The transfer film can also sustain the low shear force. As binary solid lubricants can generate more durable transfer films, and the nanocomposite can achieve the higher wearresistance and the lower friction coefficients [9-13]. As presented in Fig. 11, $\mathrm{MoS}_{2}$ can be more effective in forming the transfer layer on the worn surfaces at the initial stage of the tribological process in comparison to $\mathrm{WS}_{2}$, However, $\mathrm{WS}_{2}$ affords better lubricating properties compared with $\mathrm{MoS}_{2}$ [4]. Therefore, the $\mathrm{Ag}-\mathrm{WS}_{2}-\mathrm{MoS}_{2}$ nanocomposite can rapidly form a transfer film at the initial stage, which results in a friction coefficient as low as 0.12 and a wear rate as low as $2.17 \times 10^{-6} \mathrm{~mm}^{3} /(\mathrm{N} \cdot \mathrm{m})$ in a high-purity nitrogen atmosphere.

\section{Conclusions}

1) The $\mathrm{Ag}-\mathrm{WS}_{2}-\mathrm{MoS}_{2}$ nanocomposite exhibits a bending strength of $187.5 \mathrm{MPa}$ and a hardness of 73.4 HB. The semi-coherent interface of W (111) and Ag (111) results in an improvement of the interfacial bonding between the solid lubricants and Ag matrix, where were semi-coherent, contributed to the improved mechanical properties of the nanocomposite.

2) The nanocomposite containing binary solid lubricants exhibited an improvement in tribological performance, with a low friction coefficient of 0.12 and a low wear rate of $2.17 \times 10^{-6} \mathrm{~mm}^{3} /(\mathrm{N} \cdot \mathrm{m})$ in a high-purity nitrogen atmosphere.

(3) From the outmost surface to the subsurface, the solid lubricant content decreased. The solid lubricant content in the lubricating film was 2.3 times higher than that in the matrix. The film thickness of the lubricating film increased with a decrease in the sliding speed, and the thickest lubricating film was approximately $125 \mathrm{~nm}$ with the sliding speed of $0.01 \mathrm{~m} / \mathrm{s}$. When the lubricating film thickness exceeded $90 \mathrm{~nm}$, a smooth contact of the pins and discs was achieved.

\section{Acknowledgements}

The authors would like to thank National Natural Science Foundation of China (Grant No. 51674304) for the financial support provided.

Open Access This article is licensed under a Creative Commons Attribution 4.0 International License, which permits use, sharing, adaptation, distribution and reproduction in any medium or for-mat, as long as you give appropriate credit to the original author(s) and the source, provide a link to the Creative Commons licence, and indicate if changes were made.

The images or other third party material in this article are included in the article's Creative Commons licence, unless indicated otherwise in a credit line to the material. If material is not included in the article's Creative Commons licence and your intended use is not permitted by statutory regulation or exceeds the permitted use, you will need to obtain permission directly from the copyright holder.

To view a copy of this licence, visit http://creativecommons.org/licenses/by/4.0/.

\section{References}

[1] Uflyand I E, Zhinzhilo V A, Burlakova V E. Metalcontaining nanomaterials as lubricant additives: Stateof-the-art and future development. Friction 7(2): 93- 
116 (2019)

[2] Li H, Wang J H, Gao S, Chen Q, Peng L M, Liu K H, Wei X L. Superlubricity between $\mathrm{MoS}_{2}$ monolayers. $A d v$ Mater 29(27): 1701474 (2017)

[3] Xiao H P, Liu S H. 2D nanomaterials as lubricant additive: A review. Mater Des 135: 319-332 (2017)

[4] Scharf T W, Prasad S V. Solid lubricants: A review. $J$ Mater Sci 48(2): 511-531 (2013)

[5] Chhowalla M, Amaratunga G A J. Thin films of fullerenelike MoS2 nanoparticles with ultra-low friction and wear. Nature 407(6801): 164-167 (2000)

[6] Tudela I, Cobley A J, Zhang Y. Tribological performance of novel nickel-based composite coatings with lubricant particles. Friction 7(2): 169-180 (2019)

[7] Xiao J K, Wu Y Q, Zhang W, Chen J, Zhang C. Friction of metal-matrix self-lubricating composites: Relationships among lubricant content, lubricating film coverage, and friction coefficient. Friction 8(3): 517-530 (2020)

[8] Chen B B, Yang J, Zhang Q, Huang H, Li H P, Tang H, Li C S. Tribological properties of copper-based composites with copper coated $\mathrm{NbSe}_{2}$ and CNT. Mater Des 75: 24-31 (2015)

[9] Boscher N D, Carmalt C J, Parkin I P. Atmospheric pressure chemical vapour deposition of $\mathrm{NbSe}_{2}-\mathrm{TiSe}_{2}$ composite thin films. Appl Surf Sci 256(10): 3178-3182 (2010)

[10] Chen W, Wang Y, Zhang L, Feng C F, Zhou K C. The effect of hot extrusion on mechanical and tribological behavior of $\mathrm{Ag}-\mathrm{Cu} / \mathrm{MoS}_{2}$ composites. Tribol Trans 59(2): 375-384 (2016)

[11] Rajkumar K, Aravindan S. Tribological behavior of microwave processed copper-nanographite composites. Tribol Int 57: 282-296 (2013)

[12] Muratore C, Voevodin A A. Chameleon coatings: Adaptive surfaces to reduce friction and wear in extreme environments. Annu Rev Mater Res 39: 297-324 (2009)

[13] Huang S Y, Feng Y, Liu H J, Ding K W, Qian G. Electrical sliding friction and wear properties of $\mathrm{Cu}-$ $\mathrm{MoS}_{2}$-graphite-WS 2 nanotubes composites in air and vacuum conditions. Mater Sci Eng A 560: 685-692 (2013)

[14] Scharf T W, Kotula P G, Prasad S V. Friction and wear mechanisms in $\mathrm{MoS}_{2} / \mathrm{Sb}_{2} \mathrm{O}_{3} / \mathrm{Au}$ nanocomposite coatings. Acta Mater 58(12): 4100-4109 (2010)

[15] An V, Irtegov Y, de Izarra C. Study of tribological properties of nanolamellar $\mathrm{WS}_{2}$ and $\mathrm{MoS}_{2}$ as additives to lubricants. J Nanomater 2014: 865839 (2014)

[16] Meng Y, Su F H, Chen Y Z. Effective lubricant additive of nano-Ag/MWCNTs nanocomposite produced by supercritical $\mathrm{CO}_{2}$ synthesis. Tribol Int 118: 180-188 (2018)

[17] Wu J S, Li J F, Zhang L, Qian Z Y. Effects of environment on dry sliding wear behavior of silver- copper based composites containing tungsten disulfide. Trans Nonferrous Met Soc China 27(10): 2202-2213 (2017)

[18] Grandin M, Wiklund U. Wear phenomena and tribofilm formation of copper/copper-graphite sliding electrical contact materials. Wear 398-399: 227-235 (2018)

[19] Cheng J, Li F, Zhu S Y, Hao J Y, Yang J, Li W S, Liu W M. High temperature tribological properties of a nickelalloy-based solid-lubricating composite: Effect of surface tribo-chemistry, counterpart and mechanical properties. Wear 386-387: 39-48 (2017)

[20] Hu Y, Wang L, Politis D J, Masen M A. Development of an interactive friction model for the prediction of lubricant breakdown behaviour during sliding wear. Tribol Int 110: 370-377 (2017)

[21] Wu Y X, Wang F X, Cheng Y Q, Chen N P. A study of the optimization mechanism of solid lubricant concentration in $\mathrm{NiMoS}_{2}$ self-lubricating composite. Wear 205(1-2): 64-70 (1997)

[22] Krupka I, Sperka P, Hartl M. Effect of surface roughness on lubricant film breakdown and transition from EHL to mixed lubrication. Tribol Int 100: 116-125 (2016)

[23] Xiao J K, Zhang W, Liu L M, Zhang L, Zhang C. Tribological behavior of copper-molybdenum disulfide composites. Wear 384-385: 61-71 (2017)

[24] Cen H, Lugt P M. Film thickness in a grease lubricated ball bearing. Tribol Int 134: 26-35 (2019)

[25] Gonçalves D, Graça B, Campos A V, Seabra J, Leckner J, Westbroek R. On the film thickness behaviour of polymer greases at low and high speeds. Tribol Int 90: 435-444 (2015)

[26] Wang Y, Chen W, Wang T, Yang H L, Hui X D, Zhang L. Crystallization behavior of sub-surface in $(\mathrm{Zr}, \mathrm{Cu})_{95} \mathrm{Al}_{5}$ bulk metallic glass induced by different counter-face materials. Mater Des 111: 213-221 (2016)

[27] Spear J C, Ewers B W, Batteas J D. 2D-nanomaterials for controlling friction and wear at interfaces. Nano Today 10(3): 301-314 (2015)

[28] Wang Q H, Kalantar-Zadeh K, Kis A, Coleman J N, Strano M S. Electronics and optoelectronics of twodimensional transition metal dichalcogenides. Nat Nanotechnol 7(11): 699-712 (2012)

[29] Chen F Y, Feng Y, Shao H, Zhang X B, Chen J, Chen N N. Friction and wear behaviors of $\mathrm{Ag} / \mathrm{MoS}_{2} / \mathrm{G}$ composite in different atmospheres and at different temperatures. Tribol Lett 47(1): 139-148 (2012)

[30] Deng Z, Klimov N N, Solares S D, Li T, Xu H. Cannara R J. Nanoscale interfacial friction and adhesion on supported versus suspended monolayer and multilayer graphene. Langmuir 29(1): 235-243 (2013)

[31] Chen Z. Friction reduction effect of soft coatings. $J$ Tribol 141(10): 104501 (2019) 
[32] Mandrino D, Podgornik B. XPS investigations of tribofilms formed on $\mathrm{CrN}$ coatings. Appl Surf Sci 396: 554-559 (2017)

[33] Begelinger A, de Gee A W J. Failure of thin film lubrication-A detailed study of the lubricant film breakdown mechanism. Wear 77(1): 57-63 (1982)

[34] Tamura Y, Zhao H, Wang C, Morina A, Neville A. Interaction of DLC and $\mathrm{B}_{4} \mathrm{C}$ coatings with fully formulated oils in boundary lubrication conditions.

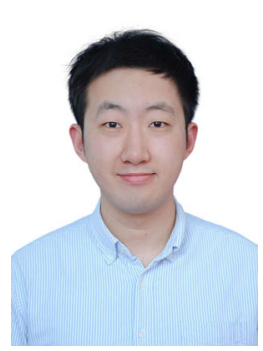

Xiao KANG. He obtained his bachelor and M.S. degrees in 2012 and 2015 from Central South University, China, majoring in mineral process engineering. $\mathrm{He}$ is currently pursuing his Ph.D.

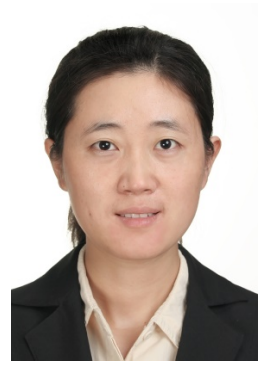

Shuang YU. She received her bachelor degree in mechanical and electrical engineering in 2005 from Harbin University of Science and Technology, China. Then, she received her Ph.D. degree in

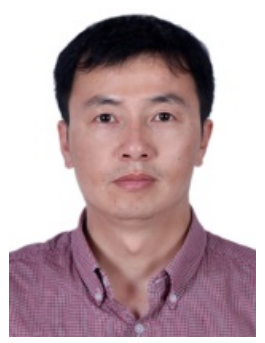

Hailin YANG. He received his M.S. degree from Hefei University of Technology in 1999 and Ph.D. degree from Central South University in 2010, majoring in material science. He joined the State Key

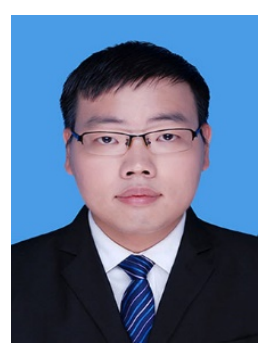

Yang SUN. He received his bachelor degree in mining engineering in 2016 from Central South University, China. After then, he is currently pursuing his Ph.D.

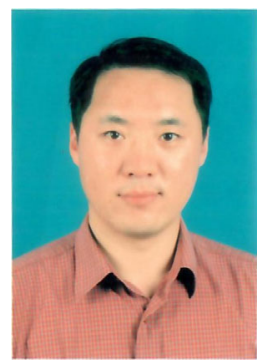

Tribol Int 93: 666-680 (2016)

[35] Rabaso P, Ville F, Dassenoy F, Diaby M, Afanasiev P, Cavoret J, Vacher B, le Mogne T. Boundary lubrication: Influence of the size and structure of inorganic fullerene-like $\mathrm{MoS}_{2}$ nanoparticles on friction and wear reduction. Wear 320: 161-178 (2014)

[36] Zhou L H, Wei X C, Ma Z J, Mei B. Anti-friction performance of $\mathrm{FeS}$ nanoparticle synthesized by biological method. Appl Surf Sci 407: 21-28 (2017)

degree in State Key Laboratory of Powder Metallurgy at the same university. His interested research areas include metal matrix selflubricating nanocomposites, powder metallurgy, and wear-resistance alloys.

mechanical and electrical engineering in 2009 from Shanghai Jiaotong University. At the same year, she joined the Shanghai Institute of Astronautical Systems Engineering. Her current position is a senior engineer. Her research areas include tribology of space mechanisms.

Laboratory of Powder Metallurgy from 2011. His current position is an associate professor of Central South University. His research areas cover powder metallurgy based new materials and advanced microstructural characterization.

degree in State Key Laboratory for Powder Metallurgy at the same university. His research interests include the sliding electrical contact system and self-assembly of the 2 dimensional (2D) particles by freeze casting.

University in 2006. His research areas include the design and manufacturing of powder metallurgy materials, the space tribology of sliding ectctrical contacts, and the friction and wear regulating of metal-based nanocomposites. 